\title{
Further generalized contraction mapping principle and best proximity theorem in metric spaces
}

\author{
Yongfu Su' and Jen-Chih Yao ${ }^{2,3^{*}}$
}

\author{
"Correspondence: \\ yaojc@mail.cmu.edu.tw \\ ${ }^{2}$ Center for General Education, \\ China Medical University, Taichung, \\ 40402, Taiwan \\ ${ }^{3}$ Department of Mathematics, King \\ Abdulaziz University, P.O. Box 80203, \\ Jeddah, 21589, Saudi Arabia \\ Full list of author information is \\ available at the end of the article
}

\begin{abstract}
The aim of this paper is to prove a more generalized contraction mapping principle. By using this more generalized contraction mapping principle, a further generalized best proximity theorem was established. Some concrete results have been derived by using the above two theorems. The results of this paper improve many important results published recently in the literature.
\end{abstract}

Keywords: contraction mapping principle; complete metric spaces; fixed point; best proximity theorem

\section{Introduction}

The Banach contraction mapping principle is a classical and powerful tool in nonlinear analysis. Weak contractions are generalizations of Banach contraction mapping which have been studied by several authors, and in particular some types of weak contractions in complete metric spaces were introduced in [1]. Let $T$ be a self-map of a metric space $(X, d)$ and $\phi:[0,+\infty) \rightarrow[0,+\infty)$ be a function. We say that $T$ is a $\phi$-contraction if

$$
d(T x, T y) \leq \phi(d(x, y)), \quad \forall x, y \in X .
$$

In 1968, Browder [2] proved that if $\phi$ is nondecreasing and right continuous, and $(X, d)$ is complete, then $T$ has a unique fixed point $x^{*}$ and $\lim _{n \rightarrow+\infty} T^{n} x_{0}=x^{*}$ for any given $x_{0} \in X$. Subsequently, his result was extended in 1969 by Boyd and Wong [3] by weakening the hypothesis on $\phi$ where it suffices to assume that $\phi$ is right upper semi-continuous (not necessarily monotonic). For a comprehensive study of relations between several contractive conditions, see $[4,5]$.

In 1973, Geraghty [6] introduced the Geraghty-contraction and obtained the fixed point theorem.

Definition 1.1 Let $(X, d)$ be a metric space. A mapping $T: X \rightarrow X$ is said to be a Geraghtycontraction if there exists $\beta \in \Gamma$ such that for any $x, y \in X$,

$$
d(T x, T y) \leq \beta(d(x, y)) d(x, y)
$$
(http://creativecommons.org/licenses/by/4.0/), which permits unrestricted use, distribution, and reproduction in any medium, provided you give appropriate credit to the original author(s) and the source, provide a link to the Creative Commons license, and indicate if changes were made. 
where the class $\Gamma$ denotes those functions $\beta:[0,+\infty) \rightarrow[0,+\infty)$ satisfying the following condition: $\beta\left(t_{n}\right) \rightarrow 1 \Rightarrow t_{n} \rightarrow 0$.

Theorem $1.2([6])$ Let $(X, d)$ be a complete metric space and $T: X \rightarrow X$ be a Geraghtycontraction. Then $T$ has a unique fixed point $x^{*}$ and for any given $x_{0} \in X$, the iterative sequence $T^{n} x_{0}$ converges to $x^{*}$.

In 2012, Samet et al. [7] defined the notion of $\alpha$-admissible mappings as follows.

Definition 1.3 ([7]) Let $\alpha: X \times X \rightarrow[0,+\infty)$ be a function. We say that a self-mapping $T: X \rightarrow X$ is $\alpha$-admissible if

$$
x, y \in X, \quad \alpha(x, y) \geq 1 \quad \Rightarrow \quad \alpha(T x, T y) \geq 1 .
$$

By using this concept, they proved some fixed point results.

Theorem 1.4 ([7]) Let $(X, d)$ be a complete metric space and $T: X \rightarrow X$ be an $\alpha$-admissible mapping. Assume that the following conditions hold:

(i) for all $x, y \in X$, we have

$$
\alpha(x, y) d(T x, T y) \leq \psi(x, y)
$$

where $\psi:[0,+\infty) \rightarrow[0,+\infty)$ is a nondecreasing function such that

$$
\sum_{n=1}^{+\infty} \psi^{n}(t)<+\infty, \quad \forall t>0
$$

(ii) there exists $x_{0} \in X$ such that $\alpha\left(x_{0}, T x_{0}\right) \geq 1$;

(iii) either $T$ is continuous or for any sequence $\left\{x_{n}\right\}$ in $X$ with $\alpha\left(x_{n}, x_{n+1}\right) \geq 1$ for all $n \geq 0$ and $x_{n} \rightarrow x$ as $n \rightarrow+\infty$, then $\alpha\left(x_{n}, x\right) \geq 1$.

Then $T$ has a fixed point.

In particular, existence of a fixed point for weak contractions and generalized contractions was extended to partially ordered metric spaces in [1, 8-19]. Among them, some involve altering distance functions. Such functions were introduced by Khan et al. in [20], where they presented some fixed point theorems with the help of such functions. We recall the definition of altering distance function.

Definition 1.5 An altering distance function is a function $\psi:[0, \infty) \rightarrow[0, \infty)$ which satisfies

(a) $\psi$ is continuous and nondecreasing;

(b) $\psi=0$ if and only if $t=0$.

Recently, Harjani and Sadarangani proved some fixed point theorems for weak contraction and generalized contractions in partially ordered metric spaces by using the altering distance function in $[11,19]$ respectively. Their results improve the theorems of [8].

Theorem 1.6 ([11]) Let $(X, \leq)$ be a partially ordered set and suppose that there exists a metric $d \in X$ such that $(X, d)$ is a complete metric space. Let $f: X \rightarrow X$ be a continuous and 
nondecreasing mapping such that

$$
d(f(x), f(y)) \leq d(x, y)-\psi(d(x, y)) \quad \text { for } x \geq y,
$$

where $\psi:[0, \infty) \rightarrow[0, \infty)$ is a continuous and nondecreasing function such that $\psi$ is positive in $(0, \infty), \psi(0)=0$ and $\lim _{t \rightarrow \infty} \psi(t)=\infty$. If there exists $x_{0} \in X$ with $x_{0} \leq f\left(x_{0}\right)$, then $f$ has a fixed point.

Theorem 1.7 ([19]) Let $(X, \leq)$ be a partially ordered set and suppose that there exists a metric $d \in X$ such that $(X, d)$ is a complete metric space. Let $f: X \rightarrow X$ be a continuous and nondecreasing mapping such that

$$
\psi d(f(x), f(y)) \leq \psi(d(x, y))-\phi(d(x, y)) \quad \text { for } x \geq y,
$$

where $\psi$ and $\phi$ are altering distance functions. If there exists $x_{0} \in X$ with $x_{0} \leq f\left(x_{0}\right)$, then $f$ has a fixed point.

Subsequently, Amini-Harandi and Emami proved another fixed point theorem for contraction type maps in partially ordered metric spaces in [10]. The following class of functions is used in [10].

Theorem 1.8 ([10]) Let $(X, \leq)$ be a partially ordered set and suppose that there exists a metric $d$ such that $(X, d)$ is a complete metric space. Let $f: X \rightarrow X$ be an increasing mapping such that there exists an element $x_{0} \in X$ with $x_{0} \leq f\left(x_{0}\right)$. Suppose that there exists $\beta \in \Gamma$ such that

$$
d(f(x), f(y)) \leq \beta(d(x, y)) d(x, y) \quad \text { for each } x, y \in X \text { with } x \geq y .
$$

Assume that either $f$ is continuous or $X$ is such that if an increasing sequence $x_{n} \rightarrow x \in X$, then $x_{n} \leq x, \forall n$. Besides, iffor each $x, y \in X$ there exists $z \in X$ which is comparable to $x$ and $y$, then $f$ has a unique fixed point.

In 2012, Yan et al. proved the following result.

Theorem 1.9 ([1]) Let $X$ be a partially ordered set and suppose that there exists a metric $d$ in $x$ such that $(X, d)$ is a complete metric space. Let $T: X \rightarrow X$ be a continuous and nondecreasing mapping such that

$$
\psi(d(T x, T y)) \leq \phi(d(x, y)), \quad \forall x \geq y,
$$

where $\psi$ is an altering distance function and $\phi:[0, \infty) \rightarrow[0, \infty)$ is a continuous function with the condition $\psi(t)>\phi(t)$ for all $t>0$. If there exists $x_{0} \in X$ such that $x_{0} \leq T x_{0}$, then $T$ has a fixed point.

Several problems can be changed as equations of the form $T x=x$, where $T$ is a given self-mapping defined on a subset of a metric space, a normed linear space, a topological vector space or some suitable space. However, if $T$ is a non-self mapping from $A$ to $B$, 
then the aforementioned equation does not necessarily admit a solution. In this case, it is worth consideration to find an approximate solution $x$ in $A$ such that the error $d(x, T x)$ is minimum, where $d$ is the distance function. In view of the fact that $d(x, T x)$ is at least $d(A, B)$, a best proximity point theorem (for short BPPT) guarantees the global minimization of $d(x, T x)$ by the requirement that an approximate solution $x$ satisfies the condition $d(x, T x)=d(A, B)$. Such optimal approximate solutions are called best proximity points of the mapping $T$. Interestingly, best proximity point theorems also serve as a natural generalization of fixed point theorems since a best proximity point becomes a fixed point if the mapping under consideration is a self mapping. Research on the best proximity point is an important topic in the nonlinear functional analysis and applications (see [21-34]).

Let $A, B$ be two nonempty subsets of a complete metric space and consider a mapping $T: A \rightarrow B$. The best proximity point problem is whether we can find an element $x_{0} \in A$ such that $d\left(x_{0}, T x_{0}\right)=\min \{d(x, T x): x \in A\}$. Since $d(x, T x) \geq d(A, B)$ for any $x \in A$, in fact, the optimal solution to this problem is the one for which the value $d(A, B)$ is attained.

Let $A, B$ be two nonempty subsets of a metric space $(X, d)$. We denote by $A_{0}$ and $B_{0}$ the following sets:

$$
\begin{aligned}
& A_{0}=\{x \in A: d(x, y)=d(A, B) \text { for some } y \in B\}, \\
& B_{0}=\{y \in B: d(x, y)=d(A, B) \text { for some } x \in A\},
\end{aligned}
$$

where $d(A, B)=\inf \{d(x, y): x \in A$ and $y \in B\}$.

It is interesting to note that $A_{0}$ and $B_{0}$ are contained in the boundaries of $A$ and $B$ respectively provided $A$ and $B$ are closed subsets of a normed linear space such that $d(A, B)>0$ $[28,29]$.

Definition 1.10 ([33]) Let $(A, B)$ be a pair of nonempty subsets of a metric space $(X, d)$ with $A_{0} \neq \emptyset$. Then the pair $(A, B)$ is said to have the P-property if and only if for any $x_{1}, x_{2} \in$ $A_{0}$ and $y_{1}, y_{2} \in B_{0}$,

$$
\left\{\begin{array}{l}
d\left(x_{1}, y_{1}\right)=d(A, B), \\
d\left(x_{2}, y_{2}\right)=d(A, B)
\end{array} \quad \Rightarrow \quad d\left(x_{1}, x_{2}\right)=d\left(y_{1}, y_{2}\right) .\right.
$$

In [14], the authors proved that any pair $(A, B)$ of nonempty closed convex subsets of a real Hilbert space $H$ satisfies the $P$-property.

In [28], $P$-property was weakened to weak $P$-property and an example satisfying $P$-property but not weak $P$-property can be found there.

Definition 1.11 ([28]) Let $(A, B)$ be a pair of nonempty subsets of a metric space $(X, d)$ with $A_{0} \neq \emptyset$. Then the pair $(A, B)$ is said to have the weak P-property if and only if for any $x_{1}, x_{2} \in A_{0}$ and $y_{1}, y_{2} \in B_{0}$,

$$
\left\{\begin{array}{l}
d\left(x_{1}, y_{1}\right)=d(A, B), \\
d\left(x_{2}, y_{2}\right)=d(A, B)
\end{array} \quad \Rightarrow \quad d\left(x_{1}, x_{2}\right) \leq d\left(y_{1}, y_{2}\right) .\right.
$$

Example ([28]) Consider $\left(R^{2}, d\right)$, where $d$ is the Euclidean distance and the subsets $A=$ $\{(0,0)\}$ and $B=\left\{y=1+\sqrt{1-x^{2}}\right\}$. 
Obviously, $A_{0}=\{(0,0)\}, B_{0}=\{(-1,1),(1,1)\}$ and $d(A, B)=\sqrt{2}$. Furthermore,

$$
d((0,0),(-1,1))=d((0,0),(1,1))=\sqrt{2}
$$

however,

$$
0=d((0,0),(0,0))<d((-1,1),(1,1))=2 .
$$

We can see that the pair $(A, B)$ satisfies the weak $P$-property but not the $P$-property.

Definition 1.12 ([34]) Let $(A, B)$ be a pair of nonempty closed subsets of a complete metric space $(X, d)$. A mapping $f: A \rightarrow B$ is said to be weakly contractive provided that

$$
d(f(x), f(y)) \leq \bar{\alpha}(x, y) d(x, y)
$$

for all $x, y \in A$, where the function $\bar{\alpha}: X \times X \rightarrow[0,1)$ holds, for every $0<a<b$, that

$$
\theta(a, b)=\sup \{\bar{\alpha}(x, y): a \leq d(x, y) \leq b\}<1
$$

Theorem 1.13 ([34]) Let $(A, B)$ be a pair of nonempty closed subsets of a complete metric space $(X, d)$ such that $A_{0} \neq \emptyset$. Let $T: A \rightarrow B$ be a weakly contractive mapping defined as in Definition 1.12. Suppose that $T\left(A_{0}\right) \subseteq B_{0}$ and the pair $(A, B)$ has the weak P-property. Then $T$ has a unique best proximity point $x^{*} \in A_{0}$ and the iteration sequence $\left\{x_{2 k}\right\}_{n=0}^{\infty}$ defined by

$$
x_{2 k+1}=T x_{2 k}, \quad d\left(x_{2 k+2}, x_{2 k+1}\right)=d(A, B), \quad k=0,1,2, \ldots
$$

converges, for every $x_{0} \in A_{0}$, to $x^{*}$.

The aim of this paper is to prove a further generalized contraction mapping principle. By using this further generalized contraction mapping principle, the authors prove a further generalized best proximity theorem. Some concrete results are derived by using the above two theorems. The results of this paper modify and improve many other important recent results.

\section{Further generalized contraction mapping principle}

In what follows, we prove the following theorem which generalizes many related results in the literature.

Theorem 2.1 Let $(X, d)$ be a complete metric space. Let $T: X \rightarrow X$ be a mapping such that

$$
\psi(d(T x, T y)) \leq \phi(d(x, y)), \quad \forall x, y \in X
$$

where $\psi, \phi:[0,+\infty) \rightarrow[0,+\infty)$ are two functions with the conditions:

(1) $\psi(a) \leq \phi(b) \Rightarrow a \leq b ;$

(2) $\left\{\begin{array}{l}\psi\left(a_{n}\right) \leq \phi\left(b_{n}\right), \\ a_{n} \rightarrow \varepsilon, \quad b_{n} \rightarrow \varepsilon\end{array} \Rightarrow \varepsilon=0\right.$. 
Then $T$ has a unique fixed point and for any given $x_{0} \in X$, the iterative sequence $T^{n} x_{0}$ converges to this fixed point.

Proof For any given $x_{0} \in X$, we define an iterative sequence as follows:

$$
x_{1}=T x_{0}, \quad x_{2}=T x_{1}, \quad \ldots, \quad x_{n+1}=T x_{n}, \quad \ldots
$$

Then, for each integer $n \geq 1$, from (2.1) and (2.2) we get

$$
\psi\left(d\left(x_{n+1}, x_{n}\right)\right)=\psi\left(d\left(T x_{n}, T x_{n-1}\right)\right) \leq \phi\left(d\left(x_{n}, x_{n-1}\right)\right) .
$$

Using condition (1) we have

$$
d\left(x_{n+1}, x_{n}\right) \leq d\left(x_{n}, x_{n-1}\right)
$$

for all $n \geq 1$. Hence the sequence $d\left(x_{n+1}, x_{n}\right)$ is nonincreasing and, consequently, there exists $r \geq 0$ such that

$$
d\left(x_{n+1}, x_{n}\right) \rightarrow r
$$

as $n \rightarrow \infty$. By using condition (2) we know $r=0$.

In what follows, we show that $\left\{x_{n}\right\}$ is a Cauchy sequence. Suppose that $\left\{x_{n}\right\}$ is not a Cauchy sequence. Then there exists $\varepsilon>0$ for which we can find subsequences $\left\{x_{n_{k}}\right\},\left\{x_{m_{k}}\right\}$ with $n_{k}>m_{k}>k$ such that

$$
d\left(x_{n_{k}}, x_{m_{k}}\right) \geq \varepsilon
$$

for all $k \geq 1$. Further, corresponding to $m_{k}$ we can choose $n_{k}$ in such a way that it is the smallest integer with $n_{k}>m_{k}$ satisfying (2.4). Then

$$
d\left(x_{n_{k}-1}, x_{m_{k}}\right)<\varepsilon
$$

From (2.4) and (2.5), we have

$$
\varepsilon \leq d\left(x_{n_{k}}, x_{m_{k}}\right) \leq d\left(x_{n_{k}}, x_{n_{k}-1}\right)+d\left(x_{n_{k}-1}, x_{m_{k}}\right)<d\left(x_{n_{k}}, x_{n_{k}-1}\right)+\varepsilon
$$

Letting $k \rightarrow \infty$, we get

$$
\lim _{k \rightarrow \infty} d\left(x_{n_{k}}, x_{m_{k}}\right)=\varepsilon .
$$

By using the triangular inequality, we have

$$
\begin{aligned}
& d\left(x_{n_{k}}, x_{m_{k}}\right) \leq d\left(x_{n_{k}}, x_{n_{k}-1}\right)+d\left(x_{n_{k}-1}, x_{m_{k}-1}\right)+d\left(x_{m_{k}-1}, x_{m_{k}}\right), \\
& d\left(x_{n_{k}-1}, x_{m_{k}-1}\right) \leq d\left(x_{n_{k}-1}, x_{n_{k}}\right)+d\left(x_{n_{k}}, x_{m_{k}}\right)+d\left(x_{m_{k}}, x_{m_{k}-1}\right) .
\end{aligned}
$$


Letting $k \rightarrow \infty$ in the above two inequalities and applying (2.6), we have

$$
\lim _{k \rightarrow \infty} d\left(x_{n_{k}-1}, x_{m_{k}-1}\right)=\varepsilon
$$

Since

$$
\psi\left(d\left(x_{n_{k}}, x_{m_{k}}\right)\right) \leq \phi\left(d\left(x_{n_{k}-1}, x_{m_{k}-1}\right)\right) .
$$

By using condition (2) we know $\varepsilon=0$, which is a contradiction. This shows that $\left\{x_{n}\right\}$ is a Cauchy sequence and, since $X$ is a complete metric space, there exists $z \in X$ such that $x_{n} \rightarrow z$ as $n \rightarrow \infty$. From (2.1) and (2.2) we have

$$
\psi\left(d\left(x_{n}, T z\right)\right) \leq \phi\left(d\left(x_{n-1}, z\right)\right)
$$

By using condition (1) we get

$$
d\left(x_{n}, T z\right) \leq d\left(x_{n-1}, z\right)
$$

so that $d\left(x_{n}, T z\right) \rightarrow 0$, as $n \rightarrow+\infty$. Therefore

$$
d(z, T z) \leq d\left(x_{n}, z\right)+d\left(x_{n}, T z\right) \rightarrow 0
$$

as $n \rightarrow+\infty$. This implies $z=T z$ and proves that $z$ is a fixed point. Next we prove the uniqueness of the fixed point. Assume that there exist two fixed points $z$ and $w$. Then from (2.1) we have that

$$
\psi(d(z, w))=\psi(d(T z, T w)) \leq \phi(d(z, w)),
$$

by using condition (2) we know $d(z, w)=0$ and hence $z=w$. This completes the proof.

Example 2.2 The following functions satisfy conditions (1) and (2) of Theorem 2.1:

$$
\text { (a) }\left\{\begin{array}{l}
\psi_{1}(t)=t, \\
\phi_{1}(t)=\alpha t,
\end{array}\right.
$$

where $0<\alpha<1$ is a constant;
(b) $\left\{\begin{array}{l}\psi_{2}(t)=t^{2}, \\ \phi_{2}(t)=\ln \left(t^{2}+1\right) ;\end{array}\right.$
(c) $\left\{\begin{array}{l}\psi_{3}(t)=t, \\ \phi_{3}(t)= \begin{cases}t^{2}, & 0 \leq t \leq \frac{1}{2}, \\ t-\frac{3}{8}, & \frac{1}{2}<t<+\infty ;\end{cases} \end{array}\right.$
(d) $\left\{\begin{array}{l}\psi_{4}(t)= \begin{cases}t, & 0 \leq t \leq 1, \\ t-\frac{1}{2}, & 1<t<+\infty,\end{cases} \\ \phi_{4}(t)= \begin{cases}\frac{t}{2}, & 0 \leq t \leq 1, \\ t-\frac{4}{5}, & 1<t<+\infty ;\end{cases} \end{array}\right.$ 
$(\mathrm{e}) \quad\left\{\begin{array}{l}\psi_{5}(t)= \begin{cases}t, & 0 \leq t<1, \\ \alpha t^{2}, & 1 \leq t<+\infty\end{cases} \\ \phi_{5}(t)= \begin{cases}t^{2}, & 0 \leq t<1 \\ \beta t, & 1 \leq t<+\infty\end{cases} \end{array}\right.$

where $0<\beta<\alpha$ are constants.

If we choose $\psi_{5}(t), \phi_{5}(t)$ in Theorem 2.1, then we can get the following result.

Theorem 2.3 Let $(X, d)$ be a complete metric space. Let $T: X \rightarrow X$ be a mapping such that

$$
\begin{aligned}
& 0 \leq d(T x, T y)<1 \quad \Rightarrow \quad d(T x, T y) \leq(d(x, y))^{2}, \\
& d(T x, T y) \geq 1 \quad \Rightarrow \quad \alpha(d(T x, T y))^{2} \leq \beta d(x, y)
\end{aligned}
$$

for any $x, y \in X$. Then $T$ has a unique fixed point and for any given $x_{0} \in X$, the iterative sequence $T^{n} x_{0}$ converges to this fixed point.

If we choose $\psi_{4}(t), \phi_{4}(t)$ in Theorem 2.1, then we can get the following result.

Theorem 2.4 Let $(X, d)$ be a complete metric space. Let $T: X \rightarrow X$ be a mapping such that

$$
\begin{aligned}
& 0 \leq d(T x, T y) \leq 1 \quad \Rightarrow \quad d(T x, T y) \leq \frac{1}{2} d(x, y), \\
& 1<d(T x, T y) \quad \Rightarrow \quad d(T x, T y) \leq d(x, y)-\frac{3}{10}
\end{aligned}
$$

for any $x, y \in X$. Then $T$ has a unique fixed point and for any given $x_{0} \in X$, the iterative sequence $T^{n} x_{0}$ converges to this fixed point.

If we choose $\psi_{3}(t), \phi_{3}(t)$ in Theorem 2.1, then we can get the following result.

Theorem 2.5 Let $(X, d)$ be a complete metric space. Let $T: X \rightarrow X$ be a mapping such that

$$
\begin{aligned}
& 0 \leq d(x, y) \leq \frac{1}{2} \quad \Rightarrow \quad d(T x, T y) \leq(d(x, y))^{2}, \\
& \frac{1}{2}<d(x, y) \quad \Rightarrow \quad d(T x, T y) \leq d(x, y)-\frac{3}{8}
\end{aligned}
$$

for any $x, y \in X$. Then $T$ has a unique fixed point and for any given $x_{0} \in X$, the iterative sequence $T^{n} x_{0}$ converges to this fixed point.

It is easy to prove the following conclusion and corollary.

Corollary 2.6 Let $\psi, \phi:[0,+\infty) \rightarrow[0,+\infty)$ be two functions with the conditions:

(i) $\psi(0)=\phi(0)$;

(ii) $\psi(t)>\phi(t), \forall t>0$;

(iii) $\psi$ is lower semi-continuous, $\phi$ is upper semi-continuous.

Then $\psi(t), \phi(t)$ satisfy conditions (1) and (2). 
Corollary 2.7 Let $(X, d)$ be a complete metric space. Let $T: X \rightarrow X$ be a mapping such that

$$
\psi(d(T x, T y)) \leq \phi(d(x, y)), \quad \forall x, y \in X
$$

where $\psi, \phi:[0,+\infty) \rightarrow[0,+\infty)$ are two functions with the conditions (i), (ii) and (iii). Then $T$ has a unique fixed point, and for any given $x_{0} \in X$, the iterative sequence $T^{n} x_{0}$ converges to this fixed point.

\section{Further generalized best proximity point theorems}

Before giving our main results, we first introduce the notion of $(\varphi, \psi)$-P-property.

Definition 3.1 Let $(A, B)$ be a pair of nonempty subsets of a metric space $(X, d)$ with $A_{0} \neq \emptyset$. Then the pair $(A, B)$ is said to have the $(\psi, \varphi)$-P-property if and only if for any $x_{1}, x_{2} \in A_{0}$ and $y_{1}, y_{2} \in B_{0}$,

$$
\left\{\begin{array}{l}
d\left(x_{1}, y_{1}\right)=d(A, B) \\
d\left(x_{2}, y_{2}\right)=d(A, B)
\end{array} \quad \Rightarrow \quad \psi\left(d\left(x_{1}, x_{2}\right)\right) \leq \varphi\left(d\left(y_{1}, y_{2}\right)\right),\right.
$$

where $\psi, \varphi:[0,+\infty) \rightarrow[0,+\infty)$ are two functions.

Theorem 3.2 Let $(A, B)$ be a pair of nonempty closed subsets of a complete metric space $(X, d)$ such that $A_{0} \neq \emptyset$. Let $\psi, \varphi, \phi:[0,+\infty) \rightarrow[0,+\infty)$ be three functions with the conditions:

$$
\begin{aligned}
& \text { (1) } \psi(a) \leq \phi(b) \Rightarrow a \leq b ; \\
& \text { (2) }\left\{\begin{array}{l}
\psi\left(a_{n}\right) \leq \phi\left(b_{n}\right), \\
a_{n} \rightarrow \varepsilon, \quad b_{n} \rightarrow \varepsilon
\end{array} \Rightarrow \varepsilon=0 ;\right. \\
& \text { (3) } \psi\left(t_{n}\right) \rightarrow 0 \Rightarrow t_{n} \rightarrow 0 ; \\
& \text { (4) } t_{n} \rightarrow 0 \Rightarrow \varphi\left(t_{n}\right) \rightarrow 0 ; \\
& \text { (5) } \varphi(a) \leq \phi(b) \Rightarrow a \leq b .
\end{aligned}
$$

Let $T: A \rightarrow B$ be a mapping such that

$$
\varphi(d(T x, T y)) \leq \phi(d(x, y)), \quad \forall x, y \in A
$$

Suppose that the pair $(A, B)$ has the $(\psi, \varphi)$-P-property and $T\left(A_{0}\right) \subseteq B_{0}$. Then there exists a unique $x^{*}$ in $A$ such that $d\left(x^{*}, T x^{*}\right)=d(A, B)$.

Proof We first prove that $B_{0}$ is closed. Let $\left\{y_{n}\right\} \subseteq B_{0}$ be a sequence such that $y_{n} \rightarrow q \in B$. It follows from the $(\psi, \varphi)$-P-property that

$$
\varphi\left(d\left(y_{n}, y_{m}\right)\right) \rightarrow 0 \quad \Rightarrow \quad \psi\left(d\left(x_{n}, x_{m}\right)\right) \rightarrow 0
$$

as $n, m \rightarrow \infty$, where $x_{n}, x_{m} \in A_{0}$ and $d\left(x_{n}, y_{n}\right)=d(A, B), d\left(x_{m}, y_{m}\right)=d(A, B)$. This together with conditions (3) and (4) implies that $\left\{x_{n}\right\}$ is a Cauchy sequence so that $\left\{x_{n}\right\}$ converges 
strongly to a point $p \in A$. By the continuity of metric $d$ we have $d(p, q)=d(A, B)$, that is, $q \in B_{0}$, and hence $B_{0}$ is closed.

Let $\bar{A}_{0}$ be the closure of $A_{0}$. We claim that $T\left(\bar{A}_{0}\right) \subseteq B_{0}$. In fact, if $x \in \bar{A}_{0} \backslash A_{0}$, then there exists a sequence $\left\{x_{n}\right\} \subseteq A_{0}$ such that $x_{n} \rightarrow x$. From (3.1) and condition (5) we have

$$
d(T x, T y) \leq d(x, y), \quad \forall x, y \in A
$$

This together with the closedness of $B_{0}$ implies that $T x=\lim _{n \rightarrow \infty} T x_{n} \in B_{0}$. That is, $T\left(\bar{A}_{0}\right) \subseteq B_{0}$.

Define an operator $P_{A_{0}}: T\left(\bar{A}_{0}\right) \rightarrow A_{0}$ by $P_{A_{0}} y=\left\{x \in A_{0}: d(x, y)=d(A, B)\right\}$. Since the pair $(A, B)$ has the $(\psi, \varphi)$-P-property and $T$ satisfies condition (3.1), we have

$$
\psi\left(d\left(P_{A_{0}} T x_{1}, P_{A_{0}} T x_{2}\right)\right) \leq \varphi\left(d\left(T x_{1}, T x_{2}\right)\right) \leq \phi\left(d\left(x_{1}, x_{2}\right)\right)
$$

for any $x_{1}, x_{2} \in \bar{A}_{0}$. This shows that $P_{A_{0}} T: \bar{A}_{0} \rightarrow \bar{A}_{0}$ is a mapping from a complete metric subspace $\bar{A}_{0}$ into itself, and it satisfies the conditions of Theorem 2.1. By using Theorem 2.1, we can get that $P_{A_{0}} T$ has a unique fixed point $x^{*}$. That is, $P_{A_{0}} T x^{*}=x^{*} \in A_{0}$. It implies that

$$
d\left(x^{*}, T x^{*}\right)=d(A, B) .
$$

Therefore, $x^{*}$ is the unique element in $A_{0}$ such that $d\left(x^{*}, T x^{*}\right)=d(A, B)$. It is easy to see that $x^{*}$ is also the unique one in $A$ such that $d\left(x^{*}, T x^{*}\right)=d(A, B)$.

Theorem 3.3 Let $(A, B)$ be a pair of nonempty closed subsets of a complete metric space $(X, d)$ such that $A_{0} \neq \emptyset$. Let $\psi, \phi:[0,+\infty) \rightarrow[0,+\infty)$ be two functions with the conditions:

(1) $\psi(a) \leq \phi(b) \quad \Rightarrow \quad a \leq b$;

(2) $\left\{\begin{array}{l}\psi\left(a_{n}\right) \leq \phi\left(b_{n}\right), \\ a_{n} \rightarrow \varepsilon, \quad b_{n} \rightarrow \varepsilon\end{array} \Rightarrow \varepsilon=0 ;\right.$

(3) $\psi\left(t_{n}\right) \rightarrow 0 \quad \Leftrightarrow \quad t_{n} \rightarrow 0$

and $\psi(t)$ is nondecreasing. Let $T: A \rightarrow B$ be a mapping such that

$$
\psi(d(T x, T y)) \leq \phi(d(x, y)), \quad \forall x, y \in A .
$$

Suppose that the pair $(A, B)$ has the weak P-property and $T\left(A_{0}\right) \subseteq B_{0}$. Then there exists a unique $x^{*}$ in $A$ such that $d\left(x^{*}, T x^{*}\right)=d(A, B)$.

Proof Let $\varphi(t)=\psi(t)$ for all $t \in[0,+\infty)$. Then the pair $(A, B)$ having the weak $P$-property implies that the pair $(A, B)$ has the $(\psi, \varphi)$-P-property. Condition (3) of Theorem 3.3 implies conditions (3), (4) of Theorem 3.2 and (3.2) implies (3.1). By using Theorem 3.2 we get the conclusion of Theorem 3.3.

If we choose $\psi_{3}(t), \phi_{3}(t)$ in Theorem 3.3, then we can get the following result. 
Theorem 3.4 Let $(A, B)$ be a pair of nonempty closed subsets of a complete metric space $(X, d)$ such that $A_{0} \neq \emptyset$. Let $T: A \rightarrow B$ be a mapping such that

$$
\begin{aligned}
& 0 \leq d(x, y) \leq \frac{1}{2} \quad \Rightarrow \quad d(T x, T y) \leq(d(x, y))^{2}, \\
& \frac{1}{2}<d(x, y) \quad \Rightarrow \quad d(T x, T y) \leq d(x, y)-\frac{3}{8}
\end{aligned}
$$

for any $x, y \in A$. Suppose that the pair $(A, B)$ has the weak P-property and $T\left(A_{0}\right) \subseteq B_{0}$. Then there exists a unique $x^{*}$ in $A$ such that $d\left(x^{*}, T x^{*}\right)=d(A, B)$.

If we choose $\psi_{4}(t), \phi_{4}(t)$ in Theorem 3.3, then we can get the following result.

Theorem 3.5 Let $(A, B)$ be a pair of nonempty closed subsets of a complete metric space $(X, d)$ such that $A_{0} \neq \emptyset$. Let $T: A \rightarrow B$ be a mapping such that

$$
\begin{aligned}
& 0 \leq d(T x, T y) \leq 1 \quad \Rightarrow \quad d(T x, T y) \leq \frac{1}{2} d(x, y), \\
& 1<d(T x, T y) \quad \Rightarrow \quad d(T x, T y) \leq d(x, y)-\frac{3}{10}
\end{aligned}
$$

for any $x, y \in X$. Suppose that the pair $(A, B)$ has the weak P-property and $T\left(A_{0}\right) \subseteq B_{0}$. Then there exists a unique $x^{*}$ in $A$ such that $d\left(x^{*}, T x^{*}\right)=d(A, B)$.

Example 3.6 Let $X=R^{2}$ and

$$
\begin{aligned}
& A=\left\{(0, y) \in R^{2}: 0 \leq y \leq 1 \text { or } y=-n^{2}, n=2,3, \ldots\right\}, \\
& B=\left\{(1, y) \in R^{2}: 0 \leq y \leq 1 \text { or }-\infty<y \leq-4+\frac{3}{10}\right\} .
\end{aligned}
$$

It is easy to see that

$$
\begin{aligned}
& A_{0}=\left\{(0, y) \in R^{2}: 0 \leq y \leq 1\right\}, \\
& B_{0}=\left\{(1, y) \in R^{2}: 0 \leq y \leq 1\right\} .
\end{aligned}
$$

Let $T: A \rightarrow B$ be defined by

$$
T(0, y)= \begin{cases}\left(1, \frac{y}{2}\right) & \text { if } 0 \leq y \leq 1, \\ \left(1,-n^{2}+\frac{3 n}{10}\right) & \text { if } y=-n^{2}, n=2,3, \ldots\end{cases}
$$

It is obvious that $A, B$ are closed sets of $R^{2}, A_{0} \neq \emptyset$, the pair $(A, B)$ has the weak $P$-property and $T\left(A_{0}\right) \subset B_{0}$. On the other hand, from the definition of $T$, it is not hard to see that

$$
\begin{aligned}
& 0 \leq|T(0, x)-T(0, y)| \leq 1 \quad \Rightarrow \quad|T(0, x)-T(0, y)|=\frac{1}{2}|(0, x)-(0, y)|, \\
& 1<|T(0, x)-T(0, y)| \Rightarrow|T(0, x)-T(0, y)| \leq|(0, x)-(0, y)|-\frac{3}{10}
\end{aligned}
$$


for all $(0, x),(0, y) \in A$. Therefore, by using Theorem 3.5 , there exists a unique $x^{*}=(0,0)$ in $A$ such that $d\left(x^{*}, T x^{*}\right)=d(A, B)=1$, where $T x^{*}=(1,0)$. Note that the above mapping $T$ is a further generalized contraction, but not a contraction. In fact, for any $\left(0,-n^{2}\right),\left(0,-m^{2}\right) \in$ $A, m>n$, we have

$$
\left|T\left(0,-n^{2}\right)-T\left(0,-m^{2}\right)\right|=m^{2}-\frac{3 m}{10}-n^{2}+\frac{3 n}{10}
$$

hence

$$
\frac{\left|T\left(0,-n^{2}\right)-T\left(0,-m^{2}\right)\right|}{\left|\left(0,-n^{2}\right)-\left(0, m^{2}\right)\right|}=1+\frac{3}{10} \frac{m-n}{(m+n)(m-n)} \rightarrow 1
$$

as $m, n \rightarrow+\infty$.

\section{Competing interests}

The authors declare that they have no competing interests.

Authors' contributions

All authors contributed equally and significantly in writing this article. All authors read and approved the final manuscript.

\section{Author details}

'Department of Mathematics, Tianjin Polytechnic University, Tianjin, 300387, China. ${ }^{2}$ Center for General Education, China Medical University, Taichung, 40402, Taiwan. ${ }^{3}$ Department of Mathematics, King Abdulaziz University, P.O. Box 80203, Jeddah, 21589, Saudi Arabia.

\section{Acknowledgements}

The second author was partially supported by the grant MOST 103-2923-E-037-001-MY3.

Received: 10 February 2015 Accepted: 30 June 2015 Published online: 17 July 2015

\section{References}

1. Yan, F, Su, Y, Feng, Q: A new contraction mapping principle in partially ordered metric spaces and applications to ordinary differential equations. Fixed Point Theory Appl. 2012, 152 (2012)

2. Browder, FE: On the convergence of successive approximations for nonlinear functional equations. Proc. K. Ned. Akad. Wet., Ser. A, Indag. Math. 30, 27-35 (1968)

3. Boyd, DW, Wong, JSW: On nonlinear contractions. Proc. Am. Math. Soc. 20, 458-464 (1969)

4. Jachymski, J: Equivalence of some contractivity properties over metrical structures. Proc. Am. Math. Soc. 125 2327-2335 (1997)

5. Jachymski, J, Jóźwik, I: Nonlinear contractive conditions: a comparison and related problems. In: Fixed Point Theory and Its Applications. Banach Center Publ., vol. 77, pp. 123-146. Polish Acad. Sci., Warsaw (2007)

6. Geraghty, M: On contractive mappings. Proc. Am. Math. Soc. 40, 604-608 (1973)

7. Samet, B, Vetro, C, Vetro, P: Fixed point theorem for $\alpha$ - $\psi$-contractive type mappings. Nonlinear Anal. 75, 2154-2165 (2012)

8. Dhutta, P, Choudhury, B: A generalization of contractions in partially ordered metric spaces. Appl. Anal. 87, $109-116$ (2008)

9. Sastry, K, Babu, G: Some fixed point theorems by altering distance between the points. Indian J. Pure Appl. Math. 30, 641-647 (1999)

10. Amini-Harandi, A, Emami, H: A fixed point theorem for contraction type maps in partially ordered metric spaces and application to ordinary differential equations. Nonlinear Anal. 72, 2238-2242 (2010)

11. Harjani, J, Sadarangni, K: Fixed point theorems for weakly contraction mappings in partially ordered sets. Nonlinear Anal. 71, 3403-3410 (2009)

12. Burgic, D, Kalabusic, S, Kulenovic, M: Global attractivity results for mixed monotone mappings in partially ordered complete metric spaces. Fixed Point Theory Appl. 2009, Article ID 762478 (2009)

13. Ciric, L, Cakid, N, Rajovic, M, Uma, J: Monotone generalized nonlinear contractions in partially ordered metric spaces. Fixed Point Theory Appl. 2008, Article ID 131294 (2008)

14. Gnana Bhaskar, T, Lakshmikantham, V: Fixed point theorems in partially ordered metric spaces and applications. Nonlinear Anal. 65, 1379-1393 (2006)

15. Lakshmikantham, V, Ciric, L: Coupled fixed point theorems for nonlinear contractions in partially ordered metric spaces. Nonlinear Anal. 70, 4341-4349 (2009)

16. Nieto, JJ, Rodriguez-López, R: Contractive mapping theorems in partially ordered sets and applications to ordinary differential equations. Order 22, 223-239 (2005)

17. Nieto, JJ, Rodriguez-López, R: Existence and uniqueness of fixed point in partially ordered sets and applications to ordinary differential equations. Acta Math. Sin. 23, 2205-2212 (2007)

18. O'Regan, D, Petrusel, A: Fixed point theorems for generalized contractions in ordered metric spaces. J. Math. Anal. Appl. 341, 1241-1252 (2008) 
19. Harjani, J, Sadarangni, K: Generalized contractions in partially ordered metric spaces and applications to ordinary differential equations. Nonlinear Anal. 72, 1188-1197 (2010)

20. Khan, MS, Swaleh, M, Sessa, S: Fixed point theorems by altering distances between the points. Bull. Aust. Math. Soc 30(1), 1-9 (1984)

21. Sadiq Basha, S: Best proximity point theorems generalizing the contraction principle. Nonlinear Anal. 74, 5844-5850 (2011)

22. Mongkolkeha, C, Cho, YJ, Kumam, P: Best proximity points for Geraghty's proximal contraction mappings. Fixed Point Theory Appl. 2013, 180 (2013)

23. Dugundji, J, Granas, A: Weakly contractive mappings and elementary domain invariance theorem. Bull. Greek Math. Soc. 19, 141-151 (1978)

24. Alghamdi, MA, Alghamdi, MA, Shahzad, S: Best proximity point results in geodesic metric spaces. Fixed Point Theory Appl. 2013, 164 (2013)

25. Nashine, HK, Kumam, P, Vetro, C: Best proximity point theorems for rational proximal contractions. Fixed Point Theory Appl. 2013, 95 (2013)

26. Karapinar, E: On best proximity point of $\psi$-Geraghty contractions. Fixed Point Theory Appl. 2013, 200 (2013)

27. Zhang, J, Su, Y, Cheng, Q: Best proximity point theorems for generalized contractions in partially ordered metric spaces. Fixed Point Theory Appl. 2013, 83 (2013)

28. Zhang, J, Su, Y, Cheng, Q: A note on 'A best proximity point theorem for Geraghty-contractions'. Fixed Point Theory Appl. 2013, 99 (2013)

29. Zhang, J, Su, Y: Best proximity point theorems for weakly contractive mapping and weakly Kannan mapping in partial metric spaces. Fixed Point Theory Appl. 2014, 50 (2014)

30. Amini-Harandi, A, Hussain, N, Akbar, F: Best proximity point results for generalized contractions in metric spaces. Fixed Point Theory Appl. 2013, 164 (2013)

31. Kannan, R: Some results on fixed points. Bull. Calcutta Math. Soc. 60, 71-76 (1968)

32. Caballero, J, Harjani, J, Sadarangani, K: A best proximity point theorem for Geraghty-contractions. Fixed Point Theory Appl. (2012). doi:10.1186/1687-1812-2012-231

33. Kirk, WA, Reich, S, Veeramani, P: Proximinal retracts and best proximity pair theorems. Numer. Funct. Anal. Optim. 24, 851-862 (2003)

34. Sun, Y, Su, Y, Zhang, J: A new method for the research of best proximity point theorems of nonlinear mappings. Fixed Point Theory Appl. 2014, 116 (2014)

\section{Submit your manuscript to a SpringerOpen ${ }^{\ominus}$ journal and benefit from:}

- Convenient online submission

Rigorous peer review

- Immediate publication on acceptance

- Open access: articles freely available online

- High visibility within the field

- Retaining the copyright to your article 